\title{
Inspiration for the future of emergency medicine
}

\author{
Elaine Tang (Meds 2015), Anthony Chow (Meds 2016) \\ Faculty Reviewer: Dr. Dave Ouellette MD FRCPC ABEM (Department of Medicine, Division of Emergency Medicine \& \\ Trauma, Critical Care Medicine)
}

Emergency medicine (EM) was born from a public demand for a high-quality emergency service that would always be available and was meant to serve as a link between out-of-hospital services and in-hospital critical care. ${ }^{1}$ Since the 1950s, hospitals have been the preferred locations for around-the-clock diagnostic testing and medical care. Originally, patients went to the emergency department (ED) after hours, when they could not access health care anywhere else. ${ }^{1}$

Today, EDs are notoriously known as places of overcrowding, long wait-times and frustrated patients. ${ }^{2}$ This will continue to be a national problem. ED crowding leads to delays in care, increased mortality, decreased patient satisfaction and physician burn-out. This problem is an every-day reality for many EM physicians, reflects a system-wide performance issue and can be an indicator of health care quality. ${ }^{3}$

The causes of ED overcrowding are multifactorial. Multiple strategies have been implemented and evaluated in an effort to improve this situation: new technologies, triage systems and care-accelerating interventions. In the following section, we have outlined and evaluated four strategies to reduce ED overcrowding.

\section{CASE 1: Hospital \& Emergency Ambulance Link (HEAL) ${ }^{4}$}

A 75 year old man with a history of chronic obstructive pulmonary disease (COPD) lives at home and is on home oxygen. Over the past week, his wife has noticed changes in his behavior. After breakfast, he complained of nausea, sweating and some shortness of breath. An ambulance was called. On arrival and initial assessment, paramedics suspected $\mathrm{CO} 2$ narcosis secondary to the high O2 setting on his home oxygen machine. ${ }^{5}$ En route to the hospital, the complete ambulance record was transmitted to the ED using a linked computer system. ${ }^{4}$ The system is comprised of a front-end mobile computer to input vitals and interventions, a database server to send the information and a workstation in the ED to receive the information. As the ambulance transported the man through the city, the nursing staff was already preparing a room and the necessary equipment for his treatment. ${ }^{4}$

BENEFITS: The advanced data transmission received by the hospital will accelerate patient triage and expedite the delivery of patient care. In addition, continuous coverage and advanced warning of medical cases will improve bed coordination, overall ED flow and may warn of any unforeseen mass casualty. ${ }^{4}$

DISADVANTAGES: Implementation of the system can be costly, particularly in larger centers. Equipment will be required for the ambulances and emergency departments and the staff will need to be trained in all system operations. In addition, it will take time to ensure a coordinated system response by the staff. ${ }^{4}$

\section{CASE 2: Fast-track non-acute patient ${ }^{6}$}

A 7-year-old boy is playing outside when he trips, falls and skins his right knee. His mother, concerned about infection and unsure of his tetanus status, takes him to the ED. Once in the ED, he is triaged appropriately to a non-acute setting and does not require an ED bed or any urgent interventions. He is taken to a desk-type consulting room where he is quickly seen by a physician dedicated to looking after the "fast-track" for that day. He is given a tetanus booster and swiftly discharged from the ED.

BENEFITS: Many emergency departments utilize separate streams for conditions such as myocardial infarction, fractured femoral neck, or critically ill/trauma patients. However, research has shown that a separate stream for minor injuries is useful in decreasing waiting times and patient complaints. ${ }^{6}$ Having a nurse practitioner or physician assistant is often sufficient to deal with minor injuries. More efficient evaluation and discharge of ED patients improves ED flow and throughput. In addition, this increases bed availability for more critically ill patients. ${ }^{6}$

DISADVANTAGES: A fast track area with chairs and cubicles requires a separate physical space and can be logistically difficult to set up. ${ }^{6}$

\section{CASE 3: Rapid Entry and Accelerated Care at Triage (REACT) ${ }^{7}$}

A 27-year-old female who recently moved into the city has been encouraged to go to the ED for a flu-like illness. It has progressively worsened over the past 2 weeks, but she believes it will improve shortly. Her co-worker believes otherwise. She didn't want to go to Hospital A because she's heard about their very long wait times, so she decides to go to Hospital B.

Hospital B has recently started the REACT program. ${ }^{7}$ The REACT program helps to streamline registration of the patient into the hospital system with a computerized integrated sign-in, patient tracking on arrival and the option for physicians to initiate a range of ancillary tests and interventions at triage. During this time ED space and beds can be arranged and readied, even prior to complete patient registration. ${ }^{7}$

BENEFITS: The REACT system helps to remove duplicate steps in the registration process and allows physicians to start ancillary tests prior to assigning patients a bed. ${ }^{7}$ This will reduce the waiting time of patients after they get to a bed, as more results from labs or imaging will be available already by the time they are admitted to the ED. Physicians will also be able to interview, diagnose and treat 


\section{THINKING ON YOUR FEET}

a patient faster without having to wait for investigations to return in between patient care. Overall, this strategy has been shown to decrease the number of people who leave the ED without being seen. ${ }^{7}$

DISADVANTAGES: This process may require additional staff available at triage and in the ED, and may require significant changes to the staff culture and processes. Early laboratory investigations and imaging tests may increase resource utilization. ${ }^{7}$

\section{CASE 4: Frequent attender intervention ${ }^{8}$}

A disheveled man smelling of alcohol wanders into the ED late at night. It is his fifth visit to the ED in the past month. He was concerned because he started feeling "woozy" after a couple of drinks tonight. The hospital staff is all familiar with him, and no one has very much patience for his antics. The ED has recently started a new volunteering program, providing compassionate care to selected homeless adults, and one of the volunteers goes over and begins talking with this man. ${ }^{8}$

Over the course of the next hour in the waiting room area, he is given a light meal while he talks to the volunteer about his family and his life. He leaves, and doesn't come back again for the rest of the year.

BENEFITS: Research shows that compassionate care for the homeless helps to decrease the subsequent use of emergency services and helps decrease repeat visitors. ${ }^{8}$ While the exact mechanism is uncertain, it is speculated that increasing satisfaction can help to reinforce confidence in the medical care received and allow patients to wait longer for self-limited symptoms to resolve before seeking medical attention. It can also increase trust and lessen patient concerns. Reduction in ED visits can decrease the healthcare costs to society. ${ }^{8}$

DISADVANTAGES: Implementation of compassionate care to homeless individuals can be difficult as this population is often unkempt, may have threatening or aggressive behaviours, and requires much more time to evaluate and treat. It can be hard to train and staff volunteers in the ED to be able to provide these services and even more difficult to find room in the ED to properly interview and counsel these patients. ${ }^{8}$

\section{CONCLUSIONS}

Many strategies shown to be effective for improving efficiency and throughput in the ED are far from universally applicable and not widely adopted. Hospitals need to establish performance indicators for prospective ongoing monitoring of ED overcrowding and invest in technology to help track these indicators. ${ }^{3}$ Addressing these issues will help benefit both the physician's and the public's health - limiting burnout amongst ER doctors while improving the quality and timeliness of care delivered to patients. ${ }^{9}$ Given that emergency room visits are increasing faster than population growth, continued research into and implementation of coping mechanisms is vital to providing quality care. ${ }^{10}$

\section{REFERENCES}

1. Sklar DP, Handel DA, Hoekstra J, Baren JM, Zink B, Hedges JR. The Future of Emergency Medicine: An Evolutionary Perspective. Acad Med. 2010 Mar;85(3): 490-5.

2. Liu SW, Hamedani AG, Brown DFM, Asplin B, Camargo CA. Established and novel initiatives to reduce crowding in emergency departments. West J Emerg Med. 2013 Mar;14(2): 85-9.

3. Affleck A, Dodd G, Drummond A, Grafstein E, Innes GD, et al. The future of emergency medicine in Canada: submission from CAEP to the Romanow Commission. Part 2. CJEM. 2002;4(6): 431-8.

4. Anantharaman V, Han LS. Hospital and emergency ambulance link: using IT to enhance emergency pre-hospital care. Int J Med Inform. 2001 May;61(2-3): 147-61.

5. O’Driscoll R. Cases from AHRQ WebM\&M: Overdose on Oxygen? Medscape, LLC. [Internet]. 2008 [cited Apr 26 2013]. Available from: http://www.medscape.org/viewarticle/572882.

6. Cooke MW, Wilson S, Pearson S. The effect of a separate stream for minor injuries on accident and emergency department waiting times. Emerg Med J. 2002 Jan;19(1): 28-30.

7. Chan TC, Killeen JP, Kelly D, Guss DA. Impact of rapid entry and accelerated care at triage on reducing emergency department wait times, lengths of stay, and rate of left without being seen. Ann Emerg Med. 2005 Dec;46(6): 491-7.

8. Redelmeier DA, Molin JP, Tibshirani RJ. A randomized trial of compassionate care for the homeless in an emergency department. Lancet. 1995 May;345(8958): 1131-4.

9. Rowe BH, Bond K, Ospina MB, Blitz S, et al. Frequency, determinants and impacts of overcrowding in emergency departments in Canada: A national survey of emergency department directors. Acad Emerg Med. 2006 May;13(5): S27

10. Falcone A. The future of Emergency Medicine - New from ACEP 2012. 2012 Oct 16 [cited Apr 26 2013]. In: Medical Emergency Professionals [Internet]. Germantown (MD): Angelo Falcone. Available from: http://www.emergencydocs.com/blog/the-futureof-emergency-medicine-news-from-acep-2012/. 